\title{
Business School
}

Department of Real Estate \& Planning

Working Papers in Real Estate \& Planning 04/08

The copyright of each Working Paper remains with the author.

If you wish to quote from or cite any Paper please contact the appropriate author. In some cases a more recent version of the paper may have been published elsewhere. 


\title{
Housing Supply and Planning Delay in the South of England*
}

\author{
Michael Ball, Phil Allmendinger and Cathy Hughes
}

\section{Department of Real Estate \& Planning, University of Reading}

\begin{abstract}
There is growing international interest in the impact of regulatory controls on the supply of housing The UK has a particularly restrictive planning regime and a detailed and uncertain process of development control linked to it. This paper presents the findings of empirical research on the time taken to gain planning permission for selected recent major housing projects from a sample of local authorities in southern England. The scale of delay found was far greater than is indicated by average official data measuring the extent to which local authorities meet planning delay targets. If these results are representative of the country as a whole, they indicate that planning delay could be a major cause of the slow responsiveness of British housing supply.
\end{abstract}

${ }^{*}$ This research was funded by the Economic and Social Research Council under grant RES-000-22-2115 


\section{Introduction}

There is growing international interest in the impact of regulatory controls on the supply of housing (Bertaud \& Malpezzi, 2001; Paul Cheshire \& Sheppard, 2004; Malpezzi \& Mayo, 1997; Monk \& Whitehead, 1999; Rose, 1989). The UK stands out as a country with particularly strict planning regulation, not only in the allocation of land to housebuilding but, also, in the mechanisms for granting of permission to build. The development control system has long been identified as a major influence upon housing supply in the UK (Evans, 1991) and there are suggestions that the situation has deteriorated. A recent study concluded: 'obtaining planning permission has always been a lengthy and bureaucratic process. And the bureaucracy is increasing' (Balen, 2006: 8). The time taken to gain planning permission is an essential part of the UK planning framework. Typically, that time is referred to as planning delay, because by definition developers cannot build until they receive official permission and, so, development can only start later than it could have done in the absence of such a regulatory requirement.

Government concern with delays in planning go back to at least the 1970s, though concerted and largely failed efforts at reform were not attempted in earnest until the 1980s (Allmendinger and Thomas, 1998). The long UK housing boom that lasted from 1996 to 2007 exacerbated concerns. Government responded with a variety of measures, including a limited programme of deregulating planning controls; new mechanisms, including Design Codes; new planning approaches, notably Local Development Frameworks; and the introduction of performance targets linked to resource incentives for local authorities (DCLG, 2006).

With specific regard to planning delay, a benchmarking system has been introduced, which seems to have speed up the time taken to assess many applications for planning permission. $67 \%$ of major dwelling applications (defined as schemes with more than 10 houses) were decided within the 13 week target in the fourth quarter of 2007, up from $42 \%$ in 1999/00. ${ }^{1}$ Even so, developers and others in the private and public sectors continue to express concern about planning delays. On-going government reviews, such as the Killian-Pretty Review, and an investigation by the National Audit Office aim to identify reasons for delay in deciding planning applications and make recommendations for improvement.

A major problem with debate over planning delay is the paucity of empirical information currently available that measures it or identifies causes (Barker 2004 and 2006). The principal source of public information is official data published on the percentage of planning permissions related to major residential developments that are processed within 13 weeks. ${ }^{2}$ This is a benchmark laid down by government to encourage local authorities to speed up the performance of the planning process. There are incentives associated with meeting the benchmark, because central government is willing to pay higher levels of grant to local authorities meeting it. Over the period 2003-2011 such incentives will amount to around $f 1 \mathrm{bn}$.

The data on proportions of planning applications determined within specific time periods refer only to averages for all planning permissions which limit their use. In 2004, for example, large developments comprised only $3 \%$ of planning applications submitted in England as a whole. So, when local authorities appear to meet their targets, potential extensive delays on large schemes

\footnotetext{
1 Communities and Local Government Planning Statistics: http://www.communities.gov.uk/documents/planningandbuilding/ 2 ibid.
} 
would not become apparent from the aggregate data on delay. Even so-called major planning applications may be about relatively trivial matters and, so, averages for them alone may also look significantly better than developers' experiences with actual projects.

Most importantly, targets based on planning permissions often do not measure the length of time taken for a site to pass through the development control process, because often multiple planning applications are required. Consequently, for accurate measurement of planning delays, schemes have to be followed through from initial enquiries to final permissions to understand the full extent of the time taken to progress a development through planning procedures.

The purpose of this paper is to undertake such a measurement task by quantifying the scale of delay by investigating the time taken in development control by sites in a sub-region of South East England. The results show that the scale of time taken is often substantial and that sites rarely meet the 13 week target set for individual planning permissions. These findings, we should like to suggest, indicate that the problem of delay is indeed significant and, if they are representative of the country as a whole, suggest that delay may be a major barrier to improving housing supply elasticities.

What follows provides a brief outline of the nature of the British approach to planning and the content of the development control part of it. Then, the next section specifies the approach that is taken here to measure the time taken for sites to progress through the planning system. Delay in the British approach cannot simply be put down to time in the planning process as developers may adopt time consuming strategies, which they believe increase the chance of winning ultimate planning approval. That section also explains why a conservative methodology of measuring planning delay was adopted in order to be able to rely on publically accessible written evidence. The subsequent section presents the results and a concluding section highlights some implications of them. It should be emphasised at the start that the analysis here is focused on providing estimates of the scale of planning delay within the British planning system. No attempt is made to examine the causes of the measured delay. Instead, such exercises are provided in some forthcoming companion papers.

\section{The nature of the UK planning process}

The UK planning system differs from the more common zoning approach to regulating the development of land and property in its separation of plan from permission. As a broad generalisation, zoning-based approaches provide significant certainty concerning future development by combining plan with permission. In other words, zoning based plans confer permission to develop in accordance with the regulations therein and building permits are issued on the basis of conformity with zoning criteria and building regulations. By contrast, discretionary based approaches like the British one require separate planning permission to develop that may or may not follow the plan, which typically is much broader and general in content, with more flexible requirements, than those of a legally enforceable zone plan. The UK approach thereby weakens the link between the plan and its implementation (Booth, 2003).

Not only is the link between the plan and permission weak but there is also significant discretion for local planners in dealing with applications. Section 70 of the 1990 Town and Country Planning Act requires that, in dealing with an application for planning permission, the local planning authority shall 'have regard to the provisions of the development plan, so far as material to the application, 
and to any other material considerations'. The courts have held that it is enough for planning authorities to simply consider the development plan and, so, it may turn out in practice have little bearing on final decisions concerning whether schemes should be permitted or not.

This discretion is regarded as useful and has been at the core of the modern British approach to planning since its inception in the late 1940s (Culllingworth, 1975; 1979). It is argued to bring potential flexibility with regarded to the regulation of specific developments; to enable changing circumstances to be brought to bear rapidly in decision-making; and, more widely, to assist in meeting the aim of achieving underlying planning policy goals. Such benefits of flexibility are impossible in zoning ordinances because they are fixed and apply to all developments and hold for long periods of time without change (Booth, 2003). However, with such flexibility come costs; one of which is the greater time required to evaluate individual projects. Furthermore, the approach significantly increases key areas such as public and statutory body consultation, because not only is there consultation over the constituents of land-use plans themselves but also over every individual development as its proponents apply for planning permission. Such consultation processes are timeconsuming and may be necessary more than once if multiple applications for a site are required.

Examples of the key policies that have been made possible by the discretionary character of British development control include pro-market as well as anti-market interventions. For instance, it aided an emphasis on the importance of property development in local economic regeneration during the 1980s when the Thatcher governments wished to downplay the role of pre-existing development plans, which were inhibiting local property market activity (Allmendinger and Thomas, 1998; Allmendinger, 2003).

However, more recently, the growth in the importance of environmental concerns and increasing demands for local people to have a greater say in planning matters led to the introduction of changes in the weight placed on the development plan in determining planning applications (Allmendinger and Tewdwr-Jones, 2000). Legislation first introduced in 1991 and then updated in 2004 requires that any determination of an application 'must be made in accordance with the plan unless material considerations indicate otherwise' (S. 38(6) of the 2004 Planning and Compulsory Purchase Act). This was seen by some as a move towards a more zoning based approach in creating greater certainty, though its impact has been undermined for two reasons. First, many plans provide little certainty or guidance because they are out of date or are too general in content to be relevant. Second, decision makers can still decide that 'material considerations' outweigh the policies and intentions of a pre-given local plan. The result is that the UK system remains characterised by considerable discretion in the consideration of individual planning applications (Booth, 2003; Ball and Allmendinger, 2006).

Development control in the UK applies to all forms of development and, so, is dominated by the examination of many minor developments, including alterations to existing properties. Furthermore, in principle, minor and major developments are subject to the same processes. However, in practice, major developments are subject to much greater scrutiny. Another complication is that whilst major developments are expected to conform to the development plan, many residential sites will not lie within its remit because they are 'windfall' brownfield sites arising from the proposed conversion of an existing urban land-use or derelict industrial land into housing. In such cases the development plan will normally contain general policies rather than specific land zoning and requirements. In 
recent years around $75 \%$ of new housebuilding has been on such brownfield sites (DCLG, 2007a). Such a situation further undermines the aforementioned move towards greater certainty in emphasising the primacy of the plan in determining the outcomes of planning applications.

Ultimately, the right to develop depends on the decision and discretion of planning committees of locally elected councillors that have final say on whether permission within their jurisdiction will be granted. Their decision-making will be based on expert planning advice from an assigned development control officer (who might change during the stages faced by a developer when trying to win permission for a specific project). Where brownfield or windfall sites are concerned, the principle of development is normally acceptable but the detailed of what is acceptable varies considerably between local authorities, on the opinions of specific planning officers, and on variations in the judgement of planning committees.

There has been little research on these relatively complex administrative processes (though see Davies, 1980; Crow, 1996; Kitchen, 1997; Booth, 2003). Here, for simplicity, they will collectively be called 'planning' or personalised as 'the planner' from now on. The objective here is not to examine in any great detail why the planning system behaves and produces the results it does. Rather it is to measure some outcomes of its existence, particularly those that relate to planning delay.

When developers are refused permission, they may appeal to an independent planning inspectorate on the grounds that permission should have been granted. Judicial reviews of decisions can also be made to the courts if appropriate or agreed procedures have not been followed. Planning and appeal decisions are published and widely available. Whilst not binding, they do constitute a degree of precedent in line with the English common law tradition. The idea is that similar circumstances produce apparently similar decisions. However, as the facts or circumstances of a particular proposal differ more often than not, precedent and consistency are more an aspiration than a reality. Like the status of the development plan in determining planning applications discussed above, decision makers can dismiss what appears to be a similar situation providing they have had regard to it and found differences enough to justify a departure.

The upshot of the procedures contained within development control is that there is significant uncertainty associated with the process in terms of outcomes, as they are products of protracted negotiations between developers and planners. Mayo and Sheppard (2001) refer to this type of planning as stochastic development control, as outcomes are uncertain and the parties are not operating in contexts of full information. Furthermore, none of the parties to the negotiation are obliged to reveal their true preferences and sticking points but, instead, may utilise the information revealed in negotiating positions to persuade others to adjust to their point of view. ${ }^{3}$

For example, a developer may put in one bid to secure the principle of development, then another to achieve more detailed aims which were previously kept hidden because they might have increased the risk of refusal the first time round. From the planning side, a planner might reject a particular development and cite particular grounds for doing so in the expectation that the developer will resubmit again but with a revised project more in accordance with planning preferences. At each stage, both parties may also wish to signal that they are willing to reach a compromise. Sometimes, constraints may influence decisions, such as when planners reject

\footnotetext{
${ }^{3}$ See (Raiffa, 1982) and for an application to the UK planning context (Ball, 2004).
} 
applications in order to keep within administrative guidelines on time in the knowledge that the applicant is likely to resubmit.

\section{What happens in development control?}

A typical major planning application follows a standardised process that aims to provide the planners involved and the planning authority with a range of information inputs from a variety of relevant bodies and local residents (Figure 1). Key to the process and ultimate output is the role of negotiation with the applicant and consultation with other parties, all of which takes time and increases the uncertainty of the outcome and when the decision will be made.

Issues such as design, density, highways, parking and open space provision will all be negotiated. In addition, local authorities have powers under planning legislation to secure community benefits (known in England as Section 106 agreements) from development, the most common of which is social housing. Negotiations over such community benefits are undertaken alongside site-related issues and the interaction of the two can affect each other. For example, requirements for a lower density of development will affect development value which, in turn, may impact upon the required proportion of affordable housing.

The actual process of submitting an application triggers a wide range of consultations, the results of which can affect the outcomes of previously agreed negotiations that then need to be revisited. For example, national bodies such as the Environment Agency can object to proposals in areas likely to flood or local bodies can object to proposals on the grounds of traffic impact. Whilst, in most cases, local authorities can override objections, they usually seek to accommodate such views. Finally, the ultimate decision on a significant proportion of major housing schemes will be made by elected local councillors. Such councillors do not have to follow advice and can (and do) reject (and approve) schemes against planner views. Thus the development control process is replete with uncertainty for developers and, significantly, delay.

\section{Measuring planning delay}

As noted earlier, planning permissions do not provide an adequate measure of the time developments require to achieve planning permission because any site may be subject to multiple applications for planning permission.

Such multiple applications may relate to strategies aimed at maximising the likelihood of success under the various options available under the planning system. For example, an applicant may apply for full permission for a development in all its detail, expecting it to be rejected, but then having a clearer understanding of the issues that would lead to acceptance of a modified proposal.

Alternatively, developers may apply for 'outline' permission, leaving further details for subsequent applications - the contents of which will be specified in 'reserve matters' outlined by the planning authority. Developers may appeal local planning decisions or they may come back with amended proposals after previous unsuccessful - or successful - applications. Consequently, the routes to success are varied and depend upon strategic interactions between planners and developers and the degree of acceptability of the proposed scheme.

This suggests that a fruitful focus in understanding the extent of planning delay would be on land sites and identifiable specific development proposals on them for which permission is sought and 
Figure 1. Typical UK Development Control for Major Housing Proposals

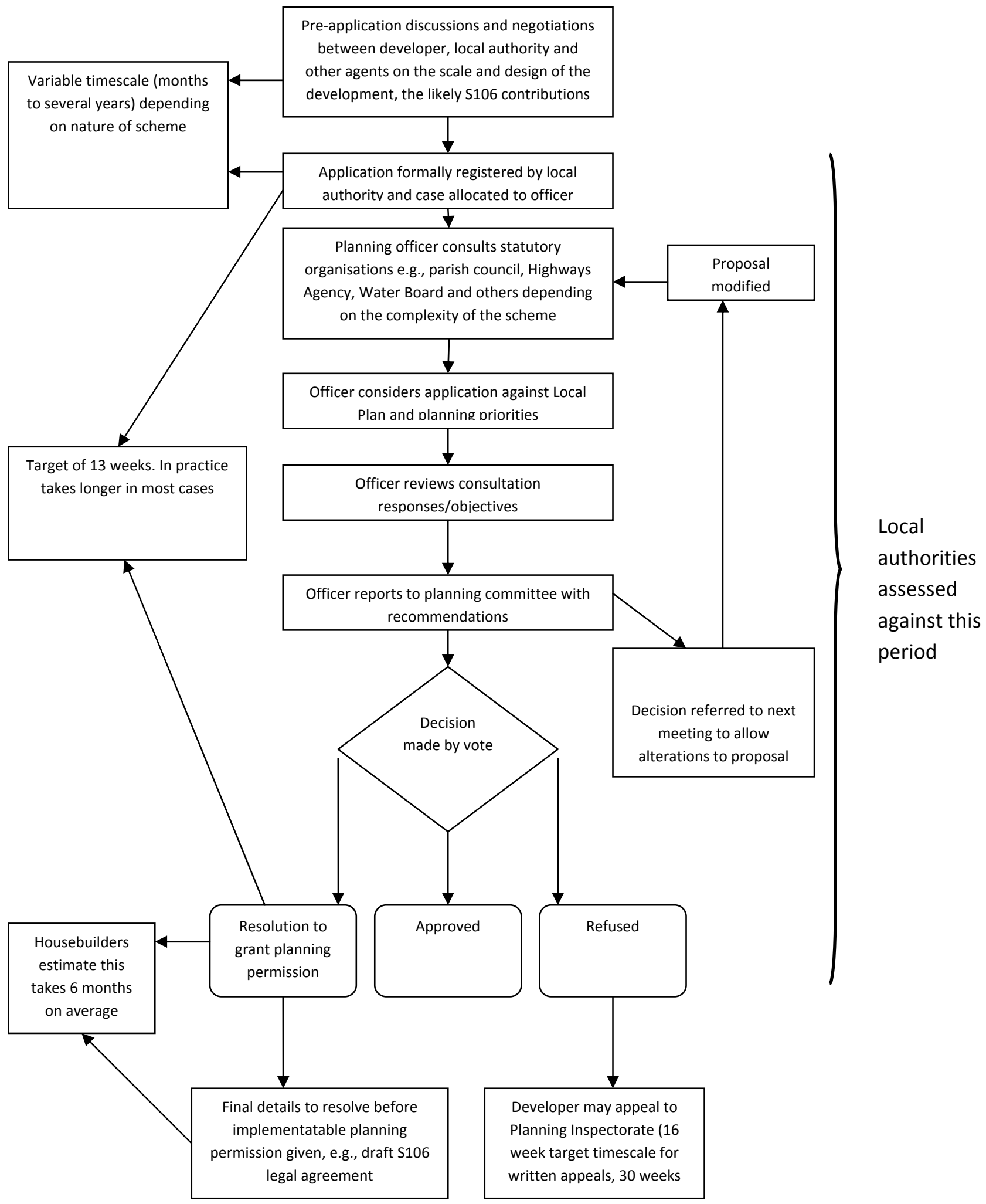

Source: Adapted from Barker Review 2004 
eventually won. Agreement from the planning authority may be achieved in one application or it make take a number of amendments to the scheme until both developer and planner are satisfied that they are in accord on what the development should be. The objective is then to measure this negotiation time and analyse its implications for the effectiveness and timeliness of the UK system of land-use planning.

With these aims in mind, information from a sample of residential developments successfully completing the planning stage of development in 2006 was assembled for 11 local authorities in Berkshire, Hampshire and Oxfordshire. The authorities are listed in Table 1. The sub-region selected for analysis is probably not representative of England as a whole. It represents one of the more affluent parts of an affluent region, the South East. It was chosen for analysis because it is in a part of the country with some of the most expensive housing outside of London, one where housing demand is far in excess of supply; partly because of the extent of local resistance to further development (P. Cheshire \& Sheppard, 2005). However, the issue here does not concern the planning-influenced level of new housing supply, because that has already been predetermined before any particular application is made for planning permission. Instead, the object of study here is the speed with which applications within those essentially pre-determined levels are processed. That speed will influence whether already agreed planning targets are going to be meet or significantly unachieved because of the slow rate at which applications are dealt with.

Only projects that eventually gain planning permission are included in the analysis, because rejected proposals are more likely to contain a wide range of atypical features. All relevant planning permissions pertaining to a specific development proposal for a site were then traced back through time, and recorded, to an initial first application. Development proposals may change in detail through the negotiation process between developer and planner but are easy to identify from planning records in their broad outlines. The characteristics of the development, the site, the developer and their agent were all noted and coded. There were some cases of changes in developer during the course of the planning process for particular sites, though such changes turned out to be rare, so that the final developer was recorded in every case. This approach has consequently the useful by-product of producing a rare insight into the world of local property development in England. ${ }^{4}$

Only one year of successful permissions was focused upon in order to control for potential time varying influences on the planning permission process. For example, it is likely that when the housing market is booming developers are more likely to want to build more homes and so apply for more permissions. This may slow down processing time as planning departments reach capacity constraints. In practice, in the study area, each authority only dealt with a handful of major residential sites in any one year and they may already have had experience of dealing with them from previous years. Additionally, narrowing the time frame limits the risk of measured times being affected by unknown changes in legislation, local authority practices and the like. Furthermore, concentrating the analysis into one sub-region helps to generate greater commonality between background factors across the surveyed local authorities, including the statutory authorities which they have to deal with.

\footnotetext{
${ }^{4}$ Paradoxically, there are many more well-known studies of local property development in nineteenth century Britain than there are of the past two decades (Ball \& Sunderland, 2001; Cannadine, 1980; Dyos, 1961).
} 


\title{
Table 1: Local planning authorities in sample
}

\author{
Basingstoke \\ East Hampshire \\ Eastleigh \\ Guildford \\ Hart \\ Portsmouth \\ West Berkshire \\ Winchester \\ Wokingham \\ Reading \\ Slough \\ Vale of White Horse
}

In practice, any local authority deals with only a limited number of sites each year. The number of sites per authority was only around 15 on average in 2006 in the selected sample, so that the sampling exercise actually captured most the major residential developments processed by each of them in that year. Subsequent data checking revealed that some sites that were believed to be completed in terms of the planning process in 2006 had further planning permissions added in 2007. As there is no way of knowing whether sites have actually been built upon, the sample is right censured, as further permissions may be applied for after the date of the last search of the databases. However, few observations are likely to be affected by this potential bias.

The system of measurement does not encompass the whole of the time of involvement of a development with the planning process of development control. It was chosen on the basis of being able to identify reliably periods of time from the available written evidence in planning authority files when planning permissions had been applied for and won. Excluded are:

1. Pre-application discussions They take place when developers informally approach planning authorities for preliminary exploration of what is likely to be approved or rejected. Such discussions are now encouraged and common. Unfortunately, not all our sample authorities kept easily obtainable records of the relevant conversations and dates, so pre-application negotiations were excluded.

2. Section 106 agreements Additional time may be spent outside of that recorded in planning applications negotiating development contributions. However, final planning permissions are not issued until s106 agreements are finalised, so most of such negotiations will be encompassed within the time applications are outstanding.

3. Completion and approval of stipulated requirements Planning permission often comes with stipulated requirements and conditions, which may themselves lead to further delay. However, it is hard to track down records of whether and when conditions were enforced, so the time associated with them was also excluded.

\section{The results}

Data on 180 sites were collected, for which in total 354 individual planning applications or appeals were identified (minor and construction-related factors were excluded, such as changes in detailing, the erection of hoardings and demolition orders). A quarter of the sites were greenfield ones and 
three-quarters brownfield, reflecting strong national and local planning preferences to re-use urban land.

\section{What was being developed?}

Most sites were relatively small scale ones, $45 \%$ generated 15 dwellings or less (Figure 2 ). The majority were high density developments of 1-2 flats. This reflected congruence at the time between planning preferences for higher density, brownfield development and developer profit-maximising strategies linked to the then strong demand for 1-2 flats from first-time buyers and property investors at the peak of the long UK house price boom of the 1990s and 2000s. ${ }^{5}$ Subsequent experience showed that too many small properties were produced at the time, the prices of which had overshot substantially, producing a glut of unsold developments in the subsequent downturn that started less than a year later in the summer of 2007. However, the objective here is not to examine in any depth why any particular dwelling type was approved but rather how long it took to gain approval.

Figure 2: Sample distribution of dwelling sizes per site

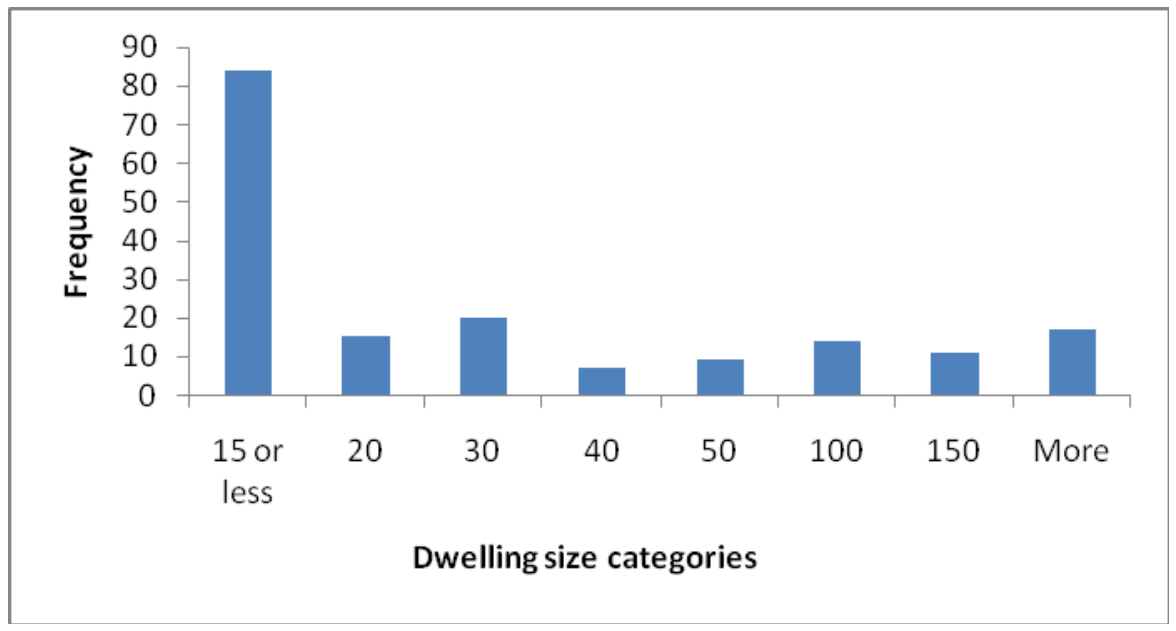

\section{Who developed them?}

The type of developer in the 11 local authority areas studied is shown in Figure 3 . The most important group are specialist housebuilders. They are divided into three size ranges. Those producing over 1,000 dwellings annually are members of the small group of national housebuilding majors. ${ }^{6}$ Those producing between 200 and 1,000 dwellings are the larger regional operators, typically operating in two or more continuous regions. Both these two types of firm will have professional management structures, with land purchasing and planning specialist managers within them.

\footnotetext{
${ }^{5}$ (Ball, 2008; Cameron, Muellbauer, \& Murphy, 2006)

${ }^{6}$ (Ball, 2006; Wellings, 2006)
} 
Figure 3: Developer types* in sub-regional sample

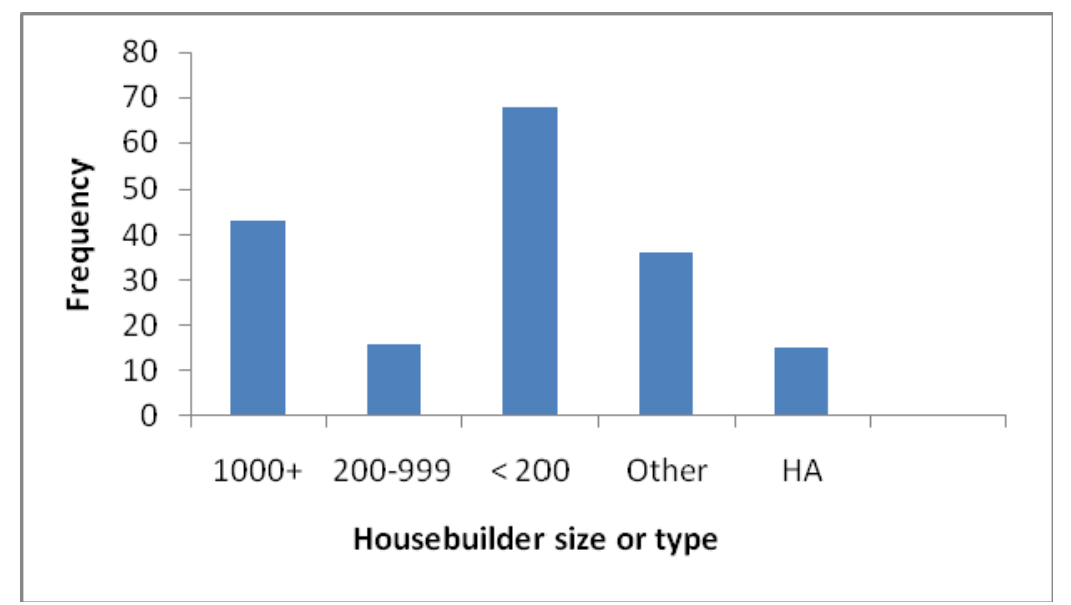

* Numbers refer to different sizes of private housebuilder; 'Other' identifies small-scale non-housebuilders; 'HA' refers to Housing Associations.

Interestingly, although they are a significant category of developers within the sample here, the national housebuilding majors' market share at $24 \%$ is substantially below the 55 per cent market share for the largest 10 firms nationally (Barker, 2004). To an extent, this is because sites are being measured rather than housing output directly, with the big firms over-represented in the larger developments producing more housing per site. However, normalising for this effect still leads to a markedly lower than national market share for the larger firms. This may be because of the nature of the small-scale urban infill developments shown above to predominate in the study sub-region. Larger developers may have weaker competitive advantages in this type of market and less knowledge of forthcoming individual brownfield land opportunities than do some small, more local producers. In fact, $40 \%$ of the sites in the sample were being developed by smaller producers building 200 or less dwellings annually. At the top of this range, such firms will be substantial enterprises with many $f$ millions of annual turnover. Even so, the majority in the sample seemed to be much smaller than that, building only few schemes at any one time.

Housing associations, social housing non-profits, represented $8 \%$ of developers in the site sample. How much of their land arose from section 106 agreements is unclear because it was rarely possible to link their schemes in with other larger housing developments, as this was often not made clear in the development control documentation.

A surprisingly, large disparate group of other developers was found to exist, being the instigators of a fifth of the schemes investigated. Some nominee firms, brass plaques in the City of London and West End, were clearly apparent; but many others came from a wide range of activities. They included private individuals apparently capitalising on the large gardens of dwellings, possibly obtained through bequests; a variety of enterprises utilising the well-trodden financial enhancement route of developing land surplus to their core requirements, ranging from schools, through engineering firms, preservation railways and charities; supermarkets fulfilling section 106 agreements to build a block of affordable flats; and individuals trying their luck as property developers. The scale and fragmented nature of the brownfield land within the study area probably helps to account for the importance of such a disparate group. 


\section{Planning process times}

Two measures of planning process time were estimated for each site. The first, termed net planning days, identified the total amount of time a planning permission was pending i.e. the sum of the dates between when an application or appeal had been lodged and a decision sent out. (Overlapping dates were not double-counted). Appeals were included within this time frame. The second, termed gross planning days, identified the full period from the first planning application to the final approval of the last planning application made with respect to the development. This second measure includes the time when the developer has no outstanding applications for the site but was either preparing a resubmission or strategically holding onto the land for market, land banking or expected changes in planning environment reasons.

Summary data for these times, measured in weeks, are shown in Table 2. The median value for time in the planning system for a residential development was almost 11 months, with the median total time lasting another 18 weeks. Many sites were delayed for far longer: $41 \%$ took over a year to be processed and $17 \%$ over 100 weeks and $6 \%$ over 150 weeks. Furthermore, the methodology used here does not encompass the full time of involvement with the planning system because of the difficulty of measure the pre- and post-application involvement of planners in discussions and monitoring.

Table 2: Development control time for individual sites

\begin{tabular}{|l|c|c|}
\hline Time in Weeks & Total planning days & Net planning days \\
\hline Mean & 84 & 58 \\
\hline Median & 62 & 44 \\
\hline Standard deviation & 72 & 44 \\
\hline
\end{tabular}

Note: 180 sites from local authority survey

Net planning days = total time with outstanding planning applications or appeals

Total planning days $=$ time from first application to final approval

These site-based times are clearly far longer than 13 week target set for individual planning permissions. Only $8 \%$ of sites were processed within that target and only a fifth within 20 weeks. It should also be remembered that most of the sites being examined here delivered only a handful of new dwellings and, so, would not seem to be particularly onerous or time-consuming schemes.

The length of time required to achieve planning permission is substantial, according to the results of this survey. Statistics can be arid, so it is perhaps worthwhile putting these results in particularly stark terms. The roughly 9,500 potential dwellings identified in the sample required 198 years total time in the planning system. During this time all the relevant parties were consulted, the schemes were evaluated and brought before Planning Committees for decisions and, then, this process was undertaken twice on average for each site and even more times for many sites, with an appeal possibly added in as well.

\section{Planning process uncertainty}

Another noticeable feature of the summary time data is the high variance around the averages, as indicated by the high standard deviations and also by the frequency distributions of total and net planning days, shown in Figures $4 a$ and $b$. They highlight the truly stochastic nature of the development control process in which two ostensibly similar developments experience widely 
differing times within the planning system and in holding periods by developers between submissions to the development control process. The oft-cited uncertainty inherent within the British approach to planning is brought out strongly in the data reported here. Of course, this is not to say that there are not systematic reasons for such differences, which are exploring in forthcoming companion papers to this one.

An important feature of site specific time variability is highlighted in Figure 5, which ranks the sample of sites from the site with the longest time period in development control (net planning time) on the left to the one with the lowest on the right and, simultaneously, plots the total planning time related to each site, which developer holding periods as well as the time when in the planning process. (The difference between the lower and upper lines in the graph is the developer holding time).

The longest net planning time was a huge 4.13 years, while the lowest was a much more modest 0.15 years, with a wide range of times per site in between the extremes (with an approximately lognormal distribution). The total days in comparison to the net ones are highly variable as is to be expected, given that sites and the developers of them are subject to stochastic influences.

Figure 4: The distribution of site planning time

a. Total Weeks per Site

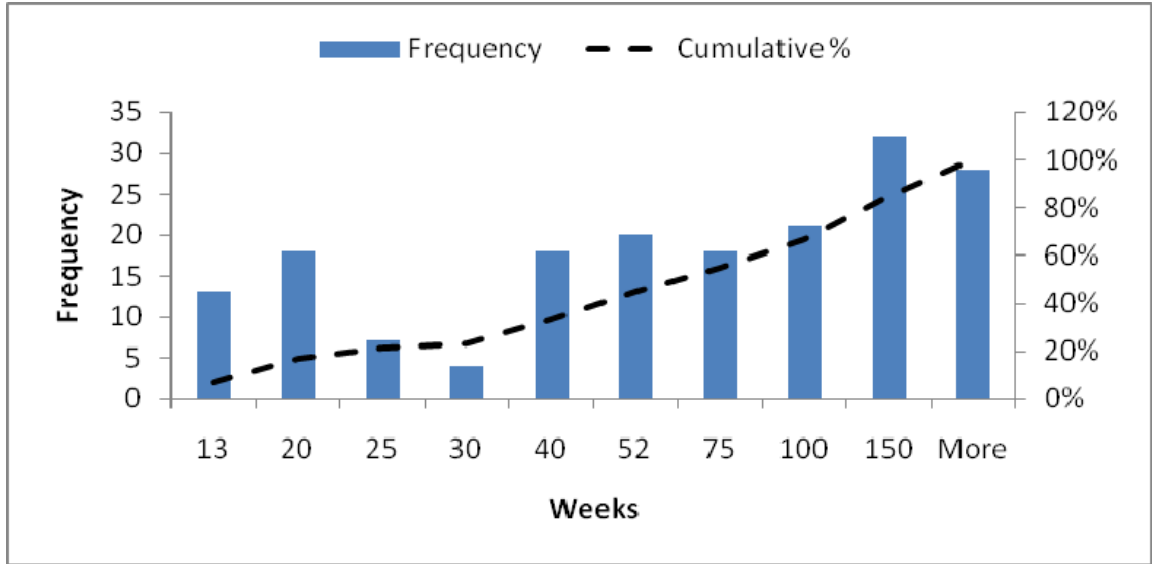

b. Net Planning Weeks per Site

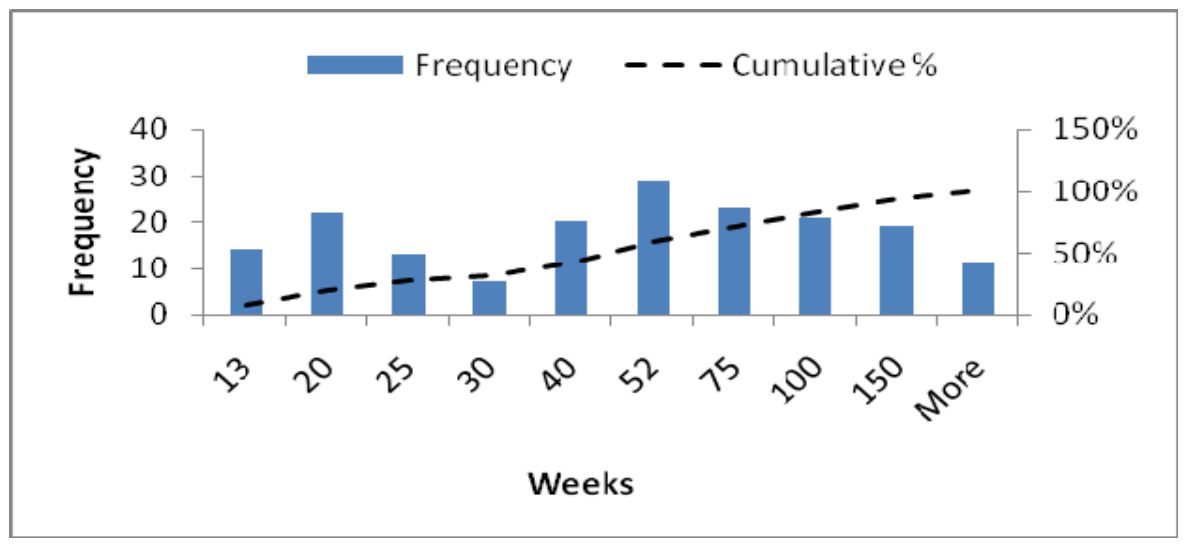


Pictorially, as shown in Figure 5, the total number of days in development control is influenced by a limited number of outlier cases, where sites were held for long holding periods. In one case, the site had a relatively modest 20 weeks in the planning system but was held for a very long time by the developer in between the two planning submissions made, making the development have the longest overall total planning-related weeks for a site. (Ironically, the developer was a small enterprise called Champion).

\section{Figure 5: Site ranking of net planning time and its relation to total planning time}

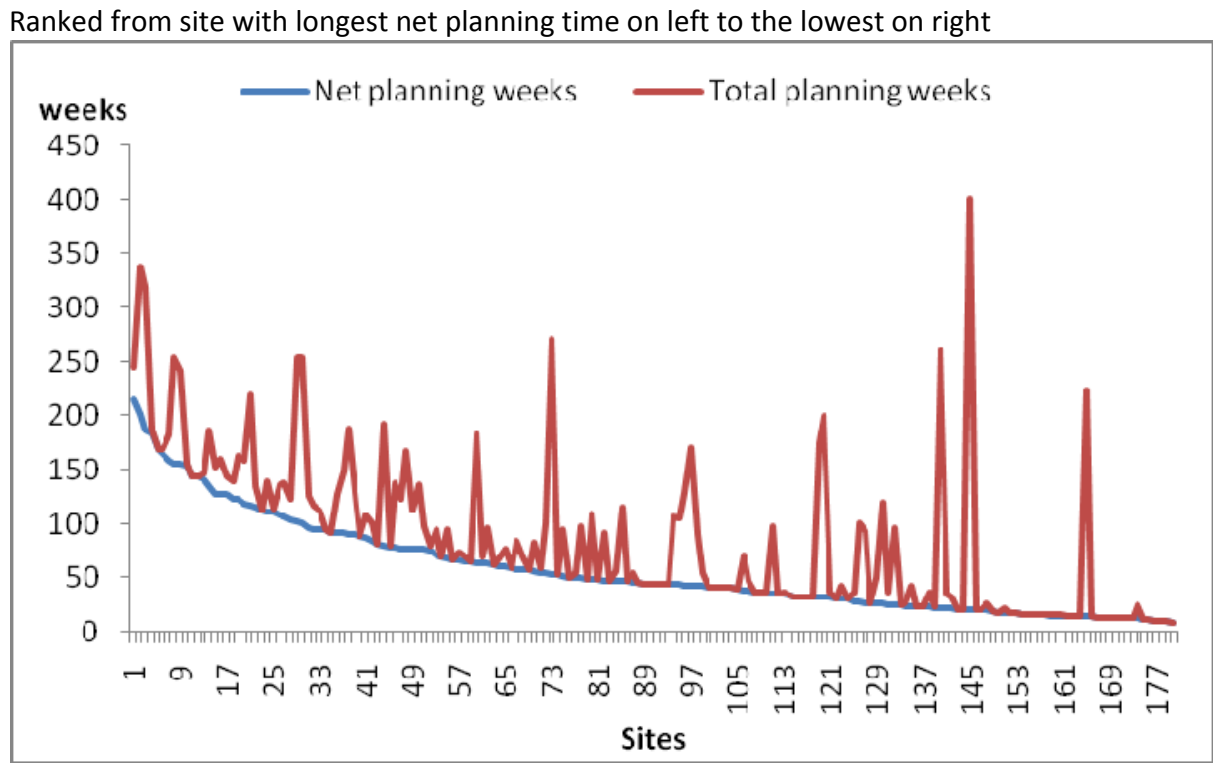

However, the extent of holding periods should not be exaggerated. Two-thirds of sites were processed within one application or had additional holding periods that were less than $25 \%$ of the net time in the planning process. Moreover, the developers with identified holding times within that group would have had to use much of the time deciding on what alterations were viable and preparing resubmissions based on them. Only $10 \%$ of sites in the sample had developer holding times above the net time sites spent in the planning system.

Overall, the results within this sample suggest, at most, limited evidence of major developer delay. Instead, most times seem consistent with developers trying to obtain planning permission for their sites as expeditiously as possible.

\section{Analysis of individual planning applications}

This section looks at the number of major individual planning permissions made per site and the time taken to grant permission from the initial submission to notification-of-decision date for each one of them. Table 3 shows, unsurprisingly, a declining hierarchy of number of submissions per site. On the one hand, the highest number of applications was 9 for a site that required 8 local applications plus 1 appeal before the development was brought to fruition. On the other hand, 39\% of all developments only went through one planning application. However, the average was two and there was a long and declining, yet still significant, tail of sites that went through increasingly more applications. 
Additional applications may not necessarily be required because the developer and local authority could not agree on matters of principle but, rather, have arisen because the developer decided to make some change to the site, such as a slight reconfiguration of dwelling types, which the planners deemed to require another major planning application. The extent to which planners should call in changes to planning stipulations and treat them as major resubmissions is a matter of some policy debate (DCLG, 2006). The data seem to suggest that the practice varies between local authorities, though for space reasons the detailed information is not reported here.

\section{Appeals}

$17 \%$ of applications went to appeal. Appeals turned out to be the lengthiest part of the development control process. It took 11 weeks more to obtain an appeal decision than it did an initial application, on average, when measured as the median value (Table 3 ).

The cost and length of the planning decision appeals process must act as a strong incentive for developers to try to come to an agreement with local planners. Planners in their negotiations must themselves be aware of the time penalty to the applicant of appeals. Moreover, appeals impose relatively limited costs on the planning authority itself. The importance of the appeals process in strengthening the hand of planning applicants against the threat of arbitrary behaviour by local planning authorities must therefore be weakened by the impact of this time dimension and the associated costs upon applicants. This would help to explain the apparently perverse behaviour of a number of appellants in the sample that either abandoned appeals or submitted parallel revised applications while appeals went on, discarding the appeal if the revisions proved acceptable to local planners.

Strategic reasons may also encourage developers to abandon appeals in mid-process, because going to appeal on one application, with the implicit chance of winning, may strengthen their hands with local planners on subsequent parallel applications. Yet, concern at the length of time and cost of providing evidence in the appeals process may be the more realistic factor and developers might prefer after all to come to terms with local planners to expedite development.

\section{Do applications speed up with repetition?}

Once planners become familiar with a development, it might be thought that the average time taken per planning permission would decline. On this hypothesis, the expectation would be that additional applications for the same site are treated more rapidly than previous ones. The results shown in Table 3 do not suggest that this is the case with first and second applications, which score similar averages. Moreover, those averages are substantially above the $13^{\text {th }}$ week benchmark. However, further applications beyond 2 do show some decline in average times, though the medians only drop to a level one or two weeks above the $13^{\text {th }}$ week benchmark and then do not decline any further. In addition, many $3^{\text {rd }}$ or more applications per site are likely to refer to specific matters rather than to whole site issues, which should be substantially easier for planners to deal with. A note of caution should be made here because after the $3^{\text {rd }}$ application, the sample drops to very small and, hence, statistically unreliable sizes. 
Table 3: Number of weeks per planning application

\begin{tabular}{|c|c|c|c|}
\hline$\frac{\frac{\text { Number of }}{\text { applications }}}{\text { per site }}$ & $\frac{\text { Number of }}{\text { applications }}$ & $\frac{\frac{\text { Mean }}{\text { weeks }}}{\underline{\underline{y}}}$ & $\frac{\text { Median }}{\underline{\text { weeks }}}$ \\
\hline $1 \mathrm{st}$ & 179 & 34 & 20 \\
\hline 2nd & 104 & 32 & 20 \\
\hline $3 r d$ & 41 & 22 & 14 \\
\hline 4th & 14 & 17 & 15 \\
\hline 5th & 9 & 21 & 13 \\
\hline 6th & 4 & 13 & 14 \\
\hline 7th & 2 & 24 & 24 \\
\hline 8th & 1 & 5 & 5 \\
\hline Appeals & 31 & 32 & 31 \\
\hline Total & 354 & 17 & 30 \\
\hline
\end{tabular}

\section{Conclusions}

The research reported here examined the time it took for sites to progress through development control in 11 local authority areas in southern England. Evidence for 180 sites was gathered, which achieved the goal of being granted planning permission to proceed with development. This time does not include all of the elements of the relationship with development control, because its excludes pre-application discussions and the time take to received approval for having met the conditions for approval laid down in the granted permission. Nonetheless, the results show that development control is a lengthy process with a considerable degree of variability and uncertainty over how long it will take.

An import conclusion of the analysis is that there is a huge difference between looking at the time with regard to individual planning permissions and those for sites as a whole. The current focus of monitoring and incentivising local authority performance is based on individual permissions alone and, hence, is probably looking at the wrong target. Development sites deliver housing, not planning permissions alone. Furthermore, this distinction may help to explain the marked difference between planner and developer perceptions of delay. Planners may think in terms of individual planning applications, because that is obviously the focus of daily work within detailed development control activity; whereas developers think in terms of sites and when and what they can build on them.

The average time for a site to gain planning permission was 11 months in the sample or just over a week per dwelling. Extrapolating these results to the national arena, the government currently has a target of building 240,000 homes a year in England annually in order to limit a growing affordability crisis. If the same amount of planning development control time was required as in the recent experience in the small part of southern England observed in this research, each tranche of 240,000 new homes would require 5000 years worth of development sites residing in the planning system waiting for scheme approvals and, worse still, that 240,000 figure is a yearly target!

Therefore, if the results produced here are reflections of reality elsewhere, they suggest that planning delay may be an important cause of the slow supply responsiveness of housebuilding in 
England. Though such a claim must inevitably be speculative, the data here may well be indicating that planning delay hinders English housing output to an even greater extent than the much more debated subject of assigned levels of housing provision articulated in central government planning guidelines, regional spatial strategies and local development frameworks. ${ }^{7}$

In terms of the potential regulatory holding back of housing supply, it is hard to avoid that the conclusion that the English system of discretionary planning permission is a huge barrier to timely development. Moreover, overcoming the barriers created is not simply about providing more resources and planners to speed up the processing of the relevant material but about sensitive issues of consultation; administrative competence and efficiency; local democracy and the role of elected officials; accountability; and the cost-benefit of public intervention. The CLG estimated the total input cost of the development control service in England in 2006 was approximately $f 290$ $£ 365$ million per annum, and fee income for $2005 / 06$ was $£ 232$ million. The cost to developers in terms of higher house prices and, more generally, in terms of lost utility and economic potential is likely to be far higher than that.

'Development control' is often referred to as the Cinderella of the UK planning system. If that is the case Cinderella is, once again, doing some spectacularly unexpected things.

\footnotetext{
${ }^{7}$ Devolution in the UK now means that it is less easy nowadays to extrapolate results to other parts of the UK, hence the emphasis here on England.
} 


\section{BIBLIOGRAPHY}

Allmendinger, P. (2003) From New Right to New Left in UK Planning, Urban Policy and Research, 21 (1): 57-80.

Allmendinger, P. and Tewdwr-Jones, M. (2000) New Labour, New Planning? The Trajectory of Planning in Post-New Right Britain, Urban Studies, 37 (8): 1379-1402.

Allmendinger, P. and Thomas, H. (1998) Urban Planning and the British New Right, Routledge.

Barker, K. (2004) Barker Review Review of Housing Supply. Final Report, HM Treasury, London.

Barker, K. (2006) Barker Review of Land Use Planning. Final Report, HM Treasury, London.

Ball, M. (2004). Co-operation with the community in property-led urban regeneration. Journal of Property Research, 21, 2, pp. 119-142.

Ball, M. (2006). Markets and Institutions in Real Estate and Construction Oxford: Blackwell Publishing.

Ball, M. (2008). European Housing Review 2008. Royal Institution of Chartered Surveyors.

Ball, M. and Sunderland, D. (2001). An Economic History of London. London: Routledge.

Ball, M. and Allmendinger, P. (2006) Rethinking the regulation of land and property markets. Final report for DCLG New Horizons Project. (Copies available from the authors.)

Booth, P. (2003) Planning by consent. The origins and nature of British development control, Routledge, London

Bertaud, A. and Malpezzi, S. (2001). Measuring the Costs and Benefits of Urban Land Use Regulation: A Simple Model with an Application to Malaysia. Journal of Housing Economics, 10, 3, pp. 393-418.

Cameron, G., Muellbauer, J. and Murphy, A. (2006). Was there a British house price bubble? Evidence from a regional panel, DP 5619 (Centre for Economic Policy Research London).

Cannadine, D. (1980). Lords and Landlords: the Aristocracy and Towns, 1774-1967. Leicester: Leicester University Press.

Cheshire, P. and Sheppard, S. (2004). Land markets and land market regulation: progress towards understanding. Regional Science and Urban Economics, 34, 6, pp. 619-637.

Cheshire, P. and Sheppard, S. (2005). The Introduction of Price Signals into Land Use Planning Decision-making: a Proposal. Urban Studies, 42, 4, pp. 647-663.

Crow, S. (1996) Development Control: the child that grew up in the cold, Planning Perspectives, 11: 399-411

Cullingworth, J.B. (1975) Reconstruction and Land Use Planning 1939-1947: Environmental Planning 1939-1969, Volume 1, HMSO, London

Cullingworth, J.B. (1979) New Towns Policy: Environmental Planning 1939-1947, Volume 4, HMSO, London

Davies, H.W.E. (1980) The relevance of development control, Town Planning Review, 51: 5-17

Department of Communities and Local Government (DCLG) (2006) Evaluation of the Planning Delivery Grant 2005/06, DCLG, London

Department of Communities and Local Government (DCLG) (2007a) Development Control Statistics 2006-2007, HMSO, London

Department of Communities and Local Government (DCLG) (2007b) Planning for a Sustainable Future: The Planning White Paper, HMSO, London 
Dyos, H. J. (1961). Victorian Suburb. A Study of the Growth of Camberwell. Leicester: Leicester University Press.

Evans, A. (1991) 'Rabbit hutches on postage stamps: planning development and political economy', Urban Studies, 28:6, 853-70.

Kitchen, T. (1997) People, politics, policies and plans: The city planning process in contemporary Britain, Paul Chapman, London

Malpezzi, S. and Mayo, S. K. (1997). Getting housing incentives right; a case study of the effects of regulation, taxes and subsidies on housing supply in Malaysia. Land Economics, 73, 3, pp. 372-391.

Monk, S. and Whitehead, C. (1999). Evaluating the economic impact of planning controls in the UK: some implications for housing Land Economics, 75, 1, pp. 74-93.

Raiffa, H. (1982). The Art and Science of Negotiation. Cambridge, Mass.: Belknap Press of Harvard University Press.

Rose, L. A. (1989). Urban land supply: Natural and contrived restrictions. Journal of Urban Economics, 25, 3, pp. 325-345.

Wellings, F. (2006). British Housebuilders. History and Analysis. Oxford: Blackwell Publishing. 